\title{
Progesterone and Melanoma Cells: An Old Story Suspended between Life and Death
}

Gabriella Moroni, Roberta Gaziano, Cristina Buè, Massimiliano Agostini, Carlo-Federico Perno, Paola Sinibaldi-Vallebona and Francesca Pica*

Department of Experimental Medicine and Surgery, University of Rome Tor Vergata, Rome, Italy

\begin{abstract}
Melanoma is a widespread cancer with poor prognosis. Female hormones are known to be capable of influencing melanoma progression but clinical data related to pregnancy, oral contraception and hormone replacement therapy are controversial. A few reports show that in vitro progesterone (PG) affects melanoma growth in nuclear progesterone receptor (nPR)-positive and nPR-negative cells, but the experimental protocols used are quite different and the results are not univocal. Further research on this topic is thus needed especially in view of the widespread use of PG in clinical practice. In this study, we used human melanoma cells (A-375), which were cultured in vitro in the presence or absence of a wide range of PG concentrations (from 0.01 to $1000 \mu \mathrm{M}$ ) in single treatment. Daily cell count, cell cycle analysis and apoptosis assay were performed. Our results show that the low PG concentrations (from 0.01 to $1.0 \mu \mathrm{M}$ ) promote a significant increase of melanoma cell proliferation but this growth-stimulatory effect is not observed at $10 \mu \mathrm{M}$ PG and the higher PG concentrations (i.e. 100 and $1000 \mu \mathrm{M}$ ) induce a cell density reduction which is the result of both cell cycle arrest and apoptosis. These findings confirm and extend previous observations reported in the international literature. A higher caution in the clinical use of progesterone is thus mandatory, since PG concentrations capable of stimulating melanoma cell proliferation are very close to those commonly used in a wide spectrum of physio-pathological conditions.
\end{abstract}

Keywords: Progesterone; Cancer; Human melanoma; Steroid hormones; Cell proliferation; Cell-cycle; Apoptosis

\section{Introduction}

Steroid hormones regulate cell proliferation, survival and development and have been involved in the origin and/or progression of cancer [1-6]. In the last decades, many epidemiological and experimental studies have suggested that steroid hormones may be etiologic factors in tumor generation, but whereas for some tumors, the link between hormones and cancer is well established, in other cases the relationship is not fully defined or even contradictory [1, 7-9].

Many human cancers, especially those of reproductive tissues, depend on progesterone (PG) [9]. PG is known to participate in the regulation of several physiological and pathological processes in mammals, such as ovarian function, growth and differentiation of the uterine endometrium and mammary gland [10]. However, PG also participates in non-reproductive processes, such as neural excitability, learning and memory, and in pathological processes like cancer [1012]. In literature, however, data exploring the relationship between progesterone and cancer are controversial. One of the main problems lies in the fact that depending on the cell type, hormonal environment, growth conditions, and developmental stage, progesterone can either stimulate or inhibit cell proliferation or promote cell differentiation [13]. It has been reported that the lifetime exposure to reproductive hormones, in particular progesterone and/or estrogens, affects the risk of breast cancer and melanoma [12]. Melanoma is a widespread skin cancer with very poor prognosis. It is an old story, however still debated, that the outcome of established melanoma is influenced by endocrine status although the acquisition of melanoma does not seem to be influenced by female sex hormones $[14,15]$. Early studies showed that female patients with malignant melanoma had some survival advantage [16], which in some studies was observed in preas opposed to post-menopausal women [17-19]. Others larger multivariate analyses, however, demonstrated that it was equally strong in pre- as well as in post-menopausal groups [20]. Parallely, the literature concerning melanoma progression in pregnancy is also controversial
[21-24], although several recent reports demonstrate that pregnancyassociated melanomas have poorer outcomes than other melanomas [25-29].

In vitro progesterone influences melanoma growth [30-33], but several melanoma cell lines have been studied and very different experimental protocols have been used, so that the results actually available in literature are not univocal. Further research on this topic is thus needed, especially in view of the widespread use of PG in clinical practice. In this study, we report the results obtained by testing in vitro the effects of a wide range of concentrations of PG on the growth and viability of human melanoma cells.

\section{Materials and methods \\ Cell Culture and Treatments}

The human melanoma A-375 cell line was purchased from the American Type Culture Collection (ATCC, Rockville, MD) and grown in DMEM supplemented with $10 \%(\mathrm{v} / \mathrm{v})$ heat-inactivated fetal calf serum (FCS) (Euroclone, Milan, Italy), $2 \mathrm{mM} \mathrm{L-glutamine,} 100 \mathrm{IU} /$ $\mathrm{ml}$ penicillin and $100 \mathrm{~g} / \mathrm{ml}$ streptomycin at $37{ }^{\circ} \mathrm{C}$ in a humidified $5 \%$ $\mathrm{CO} 2$ atmosphere. Cells were passaged two or three times a week after detachment from culture flasks with 0.05\% trypsin and 0.02\% EDTA solution in PBS. Progesterone Water-soluble was purchased from Sigma-Aldrich Chemical Company, St. Louis, MO, USA.

*Corresponding author: Francesca Pica, Department of Experimental Medicine and Surgery University of Rome Tor Vergata, Via Montpellier, 100133 Rome, Italy, Tel: 396 72596462; E-mail: pica@uniroma2.it

Received July 31, 2015; Accepted August 21, 2015; Published August 24, 2015

Citation: Moroni G, Gaziano R, Bue C, Agostini M, Perno CF et al. (2015) Progesterone and Melanoma Cells: An Old Story Suspended between Life and Death. J Steroids Horm Sci S13: 158. doi:10.4172/2157-7536.1000158

Copyright: @ 2015 Moroni G, et al. This is an open-access article distributed under the terms of the Creative Commons Attribution License, which permits unrestricted use, distribution, and reproduction in any medium, provided the original author and source are credited. 
For dose-response curve experiments, exponentially growing A-375 were seeded into 6-well plates at a density of $1.5 \times 10^{5}$ cells/well in complete culture medium (CM). After an over-night of adherence, fresh medium containing various PG concentrations (i.e. $0,01 \mu \mathrm{M}, 0,1$ $\mu \mathrm{M}, 1 \mu \mathrm{M}, 10 \mu \mathrm{M}, 100 \mu \mathrm{M}$ and $1000 \mu \mathrm{M})$ or control diluent was added to the wells and cell cultures were incubated at $37^{\circ} \mathrm{C}$ for additional 72 hours. Cell count and viability were evaluated daily in PG-treated and control cultures by light microscope after trypan blue vital-dye staining.

\section{Cell cycle kinetics and apoptosis}

Twenty-four, 48 and 72 hours post-treatment, A-375 cells were harvested and cell cycle analysis and quantification of apoptosis were performed by flow cytometry using a FACScan flow cytometer (Becton Dickinson Immunocytometry Systems, San Jose, CA, USA) equipped with an argon-ion laser $(488 \mathrm{~nm})$. The assay of cell cycle kinetics was carried out as described previously [34]. Cell cycle analysis was performed using ModFit software. Two different approaches were used to study apoptosis. The appearance of a Hypo diploid DNA peack (sub-G1 fraction) indicates the presence of an apoptotic cell population [35]. Induction of nuclear fragmentation characteristic of apoptosis was also determined by the DAPI staining of treated and untreated cells according to the standard technique [36].

\section{Statistics}

All experimental points were carried out in duplicate. Average of the duplicate samples was taken as mean value and standard error was calculated. Each experimental point was expressed as Mean \pm SEM. Each experiment was repeated at least three times. Significance of differences between PG-treated and -untreated control cells was assessed by using the Student's t test and $p$ values $\leq 0.05$ were considered significant.

\section{Results}

\section{Effect of PG addition on human melanoma A-375 cell density}

Dose and time course experiments were carried out using different PG concentrations (from 0.01 to $1000 \mu \mathrm{M}$ ) addition to human melanoma A-375 cells. As shown in Figure 1, low PG concentrations, i.e. $0.01,0.1$ and $1.0 \mu \mathrm{M}$, induce a clear-cut elevation of the A-375 cell growth above the control values $(p<0.05 v s$ untreated controls, for each concentration at each time point tested, except than $0.01 \mu \mathrm{M}$ at $24 \mathrm{~h} p=0,126)$. This effect is not observed in A-375 cells exposed to 10 $\mu \mathrm{M}$ PG, whose growth curves appear to be overlapping those of the untreated controls. Conversely, higher PG concentrations induced a dramatic reduction of cell density, which was evident at PG $100 \mu \mathrm{M}$ ( $p<0.05$ vs untreated controls at each time point tested, except than $100 \mu \mathrm{M}$ at $72 \mathrm{~h} p=0.0009$ ) and reached its maximum of inhibition at the dose PG $1000 \mu \mathrm{M}$ ( $p<0.001$ vs untreated controls at each time point tested). The block of cell proliferation induced by $100 \mu \mathrm{M}$ PG shows a recovery trend at 72 hours post-treatment, whereas $1000 \mu \mathrm{M}$ PG produce a more dramatic and prolonged effect (Figures 1 and 2). Although A-375 cells exposed to the highest PG dose were found to be suppressed up to 72 hours post-treatment, they showed a normal pattern of cell growth after being seeded in fresh medium without PG (data not shown). No macroscopic change in cell shape or spreading was observed in A-375 cells exposed to the lower doses PG (from 0.01 to $1.0 \mu \mathrm{M}$ ) when compared to the untreated control cells (data not shown). By contrast, evidence of reduced cell density was found in A-375 cells treated with the highest doses of PG, as assessed by means of microscope examination (Figure 2).

Effect of PG addition on human melanoma A-375 cell cycle kinetics and apoptosis

The effect observed on cell density in the dose-response curve experiments led us to investigate whether PG could affect cell cycle and/ or cell viability. Thus, flow-cytometry analysis was performed on A-375 cells treated or not with different PG concentrations, as shown in (Figure 3) (left panel), no significant change in the percentage of cells found in the various phases of the cell cycle was observed in cells treated with PG from 0.01 to $10.0 \mu \mathrm{M}$, throughout the whole period of observation. By contrast, cells exposed to $100 \mu \mathrm{M}$ and $1000 \mu \mathrm{M}$ PG showed an alteration of the cell cycle. In particular, we observed an increase in the percentage of the cells in S-phase with a concomitant reduction of the cells in G1phase. No significant changes in G2/M-phase were observed. Moreover, a slight increase in the percentages of sub-G1 fraction, consistent with cell death, was observed in A-375 cells exposed at the highest doses of PG, starting from 48 hours post-treatment and increasing further in the following days. This finding was confirmed by the detection of characteristic aspects of nuclear fragmentation, which were observed at microscopic examination (Figure 3). All together these results indicate that high PG concentrations induce cell cycle arrest,which appears to be most likely associated with a reduction in S-G2/M transition, rather than cell death.

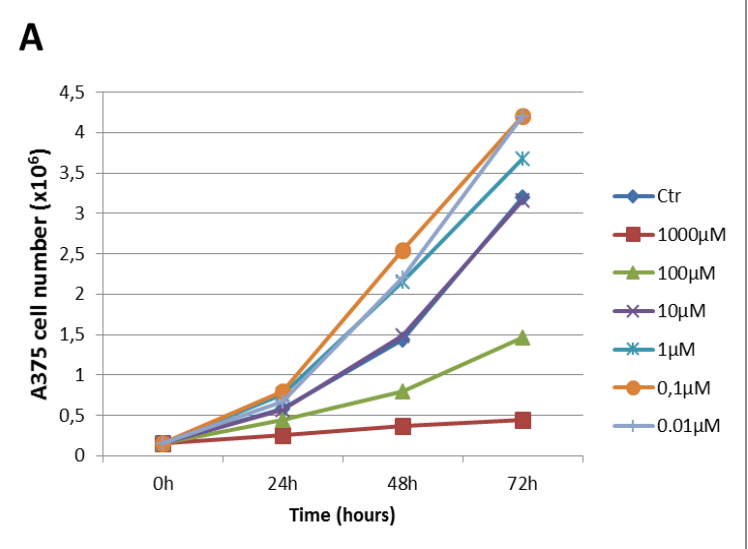

B

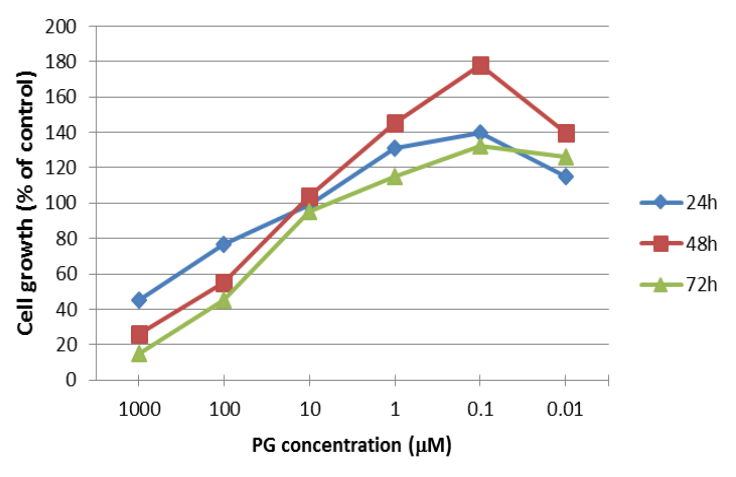

Figure 1: Effects of Progesterone on human melanoma A-375 cells. 

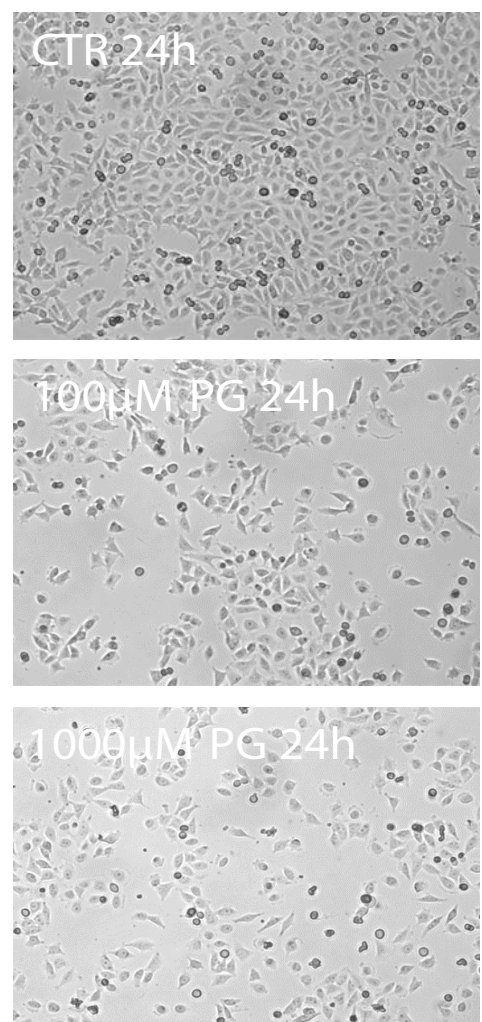

Figure 2: Effects of high-dose Progesterone on human melanoma A-375 cells.

\begin{tabular}{|c|c|c|c|c|c|}
\hline PG $(\mu \mathrm{M})$ & Time (hrs) & $\mathrm{G}_{0} / \mathrm{G}_{1}(\%)$ & $\mathrm{S}(\%)$ & $\mathrm{G}_{2} / \mathrm{M}(\%)$ & Sub-G \\
\hline 0 & 24 & 47.4 & 32.4 & 19.6 & 0.4 \\
\hline 0.01 & $"$ & 48.5 & 33,6 & 17.9 & 0.3 \\
\hline 0.1 & $"$ & 48,9 & 32.7 & 18.4 & 0.3 \\
\hline 1.0 & $"$ & 48.3 & 32.9 & 18.8 & 0.2 \\
\hline 10 & $"$ & 48.3 & 33.6 & 18 & 0.2 \\
\hline 100 & $"$ & 46 & 34.1 & 19.9 & 0.56 \\
\hline 1000 & $"$ & 24,6 & 65.8 & 9.7 & 3,7 \\
\hline PG $(\mu \mathrm{M})$ & Time (hrs) & $\mathbf{G}_{0} / \mathbf{G}_{1}(\%)$ & S (\%) & $\mathrm{G}_{2} / \mathrm{M}(\%)$ & Sub-G \\
\hline 0 & 48 & 59.4 & 26.9 & 13.7 & 0.3 \\
\hline 0.01 & “ & 61.9 & 26.7 & 11.4 & 0.3 \\
\hline 0.1 & $"$ & 63 & 23.4 & 11.7 & 0.2 \\
\hline 1.0 & $“$ & 63.1 & 25.1 & 11.8 & 0.2 \\
\hline 10 & $"$ & 64.1 & 25.1 & 10.8 & 0.4 \\
\hline 100 & $"$ & 58,6 & 30.8 & 10.7 & 1.6 \\
\hline 1000 & $“$ & 42.7 & 43.5 & 13.9 & 8.4 \\
\hline PG $(\mu \mathrm{M})$ & Time (hrs) & $\mathbf{G}_{0} / \mathbf{G}_{1}(\%)$ & S (\%) & $\mathrm{G}_{2} / \mathrm{M}(\%)$ & Sub-G ${ }_{1}$ \\
\hline 0 & 72 & 78.3 & 14.2 & 7.5 & 0.7 \\
\hline 0.01 & $"$ & 79.8 & 12.7 & 7.5 & 0.6 \\
\hline 0.1 & $"$ & 80.5 & 13.3 & 6.2 & 0.6 \\
\hline 1.0 & $"$ & 79.0 & 13.5 & 7.5 & 0.5 \\
\hline 10 & $"$ & 78.6 & 13.7 & 7.7 & 0.6 \\
\hline 100 & $"$ & 65.4 & 27.6 & 7.2 & 2 \\
\hline 1000 & " & 48 & 42.7 & 9.3 & 10.7 \\
\hline
\end{tabular}
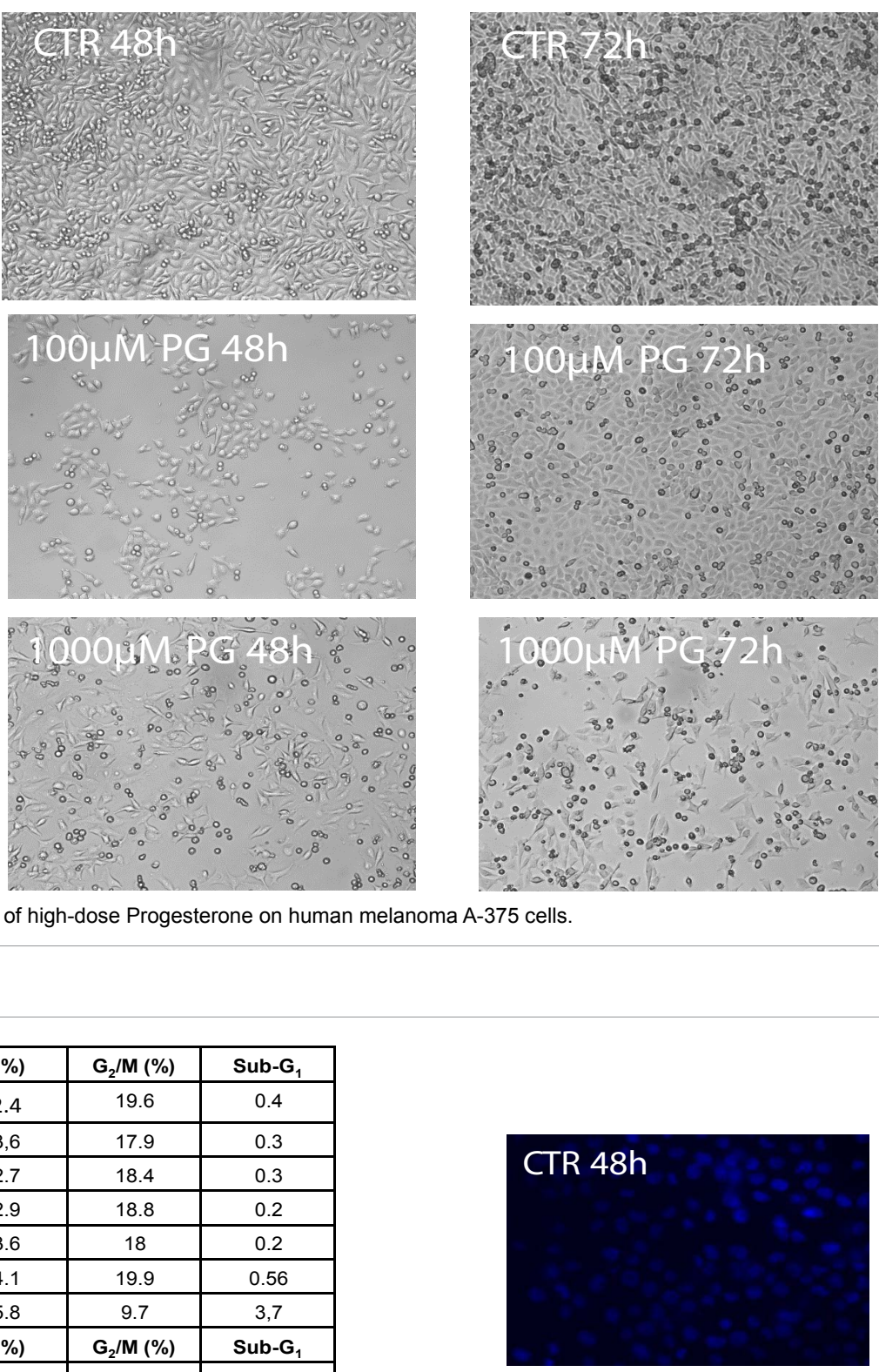
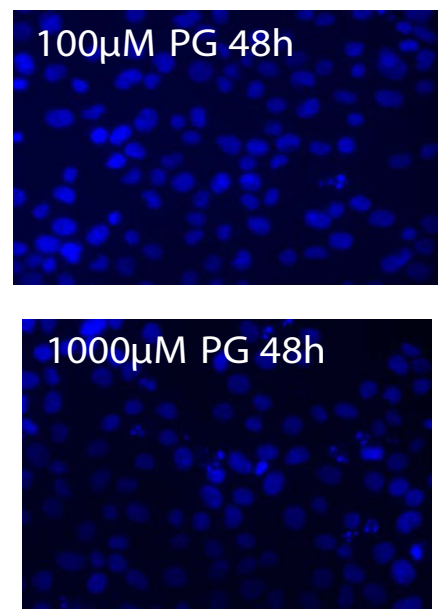

Figure 3: Effects of Progesterone on human melanoma A-375 cell cycle kinetic and apoptosis. 


\section{Discussion}

The results of our experiments show that progesterone affects the human melanoma A-375 cell growth and viability in a complex and opposite direction depending on the dose employed. Indeed, low PG concentrations (from 0.01 to $1.0 \mu \mathrm{M}$ ) induce a significant increase of cell proliferation, but the effect seems to vanish at $10 \mu \mathrm{M}$ PG and higher PG concentrations (100 and $1000 \mu \mathrm{M}$ PG) induce both cell cycle arrest and a slight increase in cell death.

A similar result was reported previously by Fang and coll. in a paper where PG treatments were carried out after an overnight of serum deprivation and the effects on the melanoma cells viability were evaluated by MTT assay exclusively 24 hours post-treatment [31]. In this regard, two considerations prompted us to repeat the experiments using a different protocol. First, previous evidence had been reported that human melanoma cells in vitro undergo a transition versus a more malignant phenotype associated with increased proliferation when exposed to stress conditions such as serum deprivation [37] and this fact could represent a potential bias for the observed PG effects. Second, the several limitations of the the MTT- and MTS-based assays have been discussed recently as well as the importance of careful evaluation of the methods used for the in vitro assessment of cell viability and proliferation[38]. Indeed, not even the cell-cycle kinetic studies appear to be reliable in this sense, as demonstrated by us in this report, since only microscopic cell counts after vital staining allowed us to check the stimulation of cell growth induced by low-dose PG. These seemingly trivial considerations, actually make us realize how important are the experimental conditions employed in the evaluation of the hormones' effects in vitro with consistent reliability, and then explain why data in the literature are often conflicting. Moreover, what is new respect to previous work, we show that both the growth-stimulatory and the growth-inhibitory effects of PG, which were obtained by means of the treatment with a single dose of low-PG $(\leq 1 \mu \mathrm{M})$ or high PG $(\geq 100 \mu \mathrm{M})$, lasted for at least 72 hours after PG addition, i.e. for the whole period of observation. Further experiments showed that the seeding of A-375 cells, which had been exposed or not to the different PG concentrations, in fresh medium without PG, produced normal cell growth patterns; conversely, the daily administration of PG to the cultures increased the hormone- induced effects, especially those induced by high-dose PG (data not shown). Other in vitro studies on different melanoma cell lines have failed to demonstrate the cell growth stimulatory effect induced by low-dose PG, although confirming that high-dose PG inhibit melanoma cell growth and viability by means of different mechanisms such as the induction of marked apoptosis and/or autophagy [32]. In our hands, the cell density reduction induced by high-dose PG was primarily the result of cell cycle arrest. However, a small contribution of cell death on cell number has been observed in our experimental setting.

The exact mechanisms underlying the effects of PG on A-375 cell growth and viability have been not completely elucidated. It is known that PG exerts its actions through various mechanisms that are classified as classical and non-classical [10]. The classical mechanisms are mediated by $\mathrm{n}-\mathrm{PR}$ and induce modifications of gene expression, whereas the non-classical ones rapidly proceed and are mediated by different pathways including the interaction with membrane receptors (mPR), ionic channels, growth factors and their receptors coupled to $G$ proteins. These last interactions are associated with increased cAMP production, phosphoinositide turnover and protein kinase $\mathrm{C}$ and MAP kinase activation [10]. The A-375 melanoma cell line used in our experiments is negative for the presence of the $\mathrm{n}-\mathrm{PR}$, but has not been characterized for the presence of $\mathrm{MPR}$ [31]. Also, the possibility that, depending on the dose employed, PG can use different cellular receptors which are present on melanoma cells, i.e. various growth factor receptors, which mediate different signal transduction pathways, cannot be ruled out [10].Finally, it is worth mentioning that melanomas are, in addition to teratocarcinomas and human breast cancer, the third tumor type with enhanced expression of HERV-K [39], and A-375 melanoma cells have been found to be positive for HERV-K encoded proteins in different studies $[37,39,40]$. Interestingly, a study performed almost thirty years ago by Ono and coll. on the human breast cancer cell line T47D, which possess different steroid receptors and is positive for HERV-K, showed that the combination of estradiol and progesterone was capable of stimulating the HERV-K genome expression [41] Recent studies also point to activation of HERV-K expression as one of the key elements contributing to both morphological and functional modifications during melanoma progression.

In conclusion, the mechanisms by which hormones induce cell proliferation in vivo are poorly understood. Further studies are needed for a better comprehension of the many and complex effects of progesterone and other steroid hormones on melanoma and other cancers. This need is made urgent especially when considering that progesterone and its synthetic progestin analogs are clinically employed as methods of contraception and in hormone replacement therapies [42-47], in the treatment of recurrent miscarriage and during assisted reproductive technologies [48]. A higher caution in the clinical use of progesterone is thus mandatory, since PG concentrations capable of stimulating melanoma cell proliferation are very close to the pharmacological doses of PG commonly used in a wide spectrum of physio-pathological conditions.

\section{Acknowledgements}

The study was supported by a grant from MIUR to CFP (Project grant: PRIN 2010PHT9NF)

\section{References}

1. Madhunapantula SV, Mosca P, Robertson GP (2010) Steroid hormones drive cancer development. Cancer Biol Ther 10: 765-766.

2. Driscoll MS, Grant-Kels JM (2007) Hormones, nevi, and melanoma: an approach to the patient. J Am Acad Dermatol 57: 919-931.

3. Lens M, Bataille $V$ (2008) Melanoma in relation to reproductive and hormonalfactors in women: current review on controversial issues. Cancer Causes Control 19: 437-442.

4. Kim JJ, Chapman-Davis E (2010) Role of progesterone in endometrial cancer Semin Reprod Med 28: 81-90.

5. Villa E. (2008) Role of estrogen in liver cancer. Womens Health (Lond Engl) 4: 41-50.

6. Keely NO, Meegan MJ (2009) Targeting tumors using estrogen receptor ligand conjugates. Curr Cancer Drug Targets 9: 370-380.

7. Freedman RA, Winer EP (2010) Adjuvant therapy for postmenopausal women with endocrine-sensitive breast cancer. Breast 19:69-75.

8. Yager JD, Davidson NE (2006) Estrogen carcinogenesis in breast cancer. N Engl J Med 354: 270-282

9. Spicer DV, Pike MC (1994) Sex steroids and breast cancer prevention. J Nat Cancer Inst Monogr 16: 139-147.

10. Hernández-Hernández OT, Camacho-Arroyo I (2013) Regulation of gene expression by progesterone in cancer cells: effects on cyclin D1, EGFR and VEGF. Mini Rev Med Chem 13: 635-642.

11. Cabrera-Muñoz E, Hernández-Hernández OT, Camacho-Arroyo I (2011) Role of progesterone in human astrocytomas growth. Curr Top Med Chem 11: 16631667

12. Conneely OM, Jericevic BM, Lydon JP (2003) Progesterone receptors in 
Citation: Moroni G, Gaziano R, Bue C, Agostini M, Perno CF et al. (2015) Progesterone and Melanoma Cells: An Old Story Suspended between Life and Death. J Steroids Horm Sci S13: 158. doi:10.4172/2157-7536.1000158

mammary gland development and tumorigenesis. J Mammary Gland Biol Neoplasia 8: 205-214.

13. Edwards DP (2005) Regulation of signal transduction pathways by estrogen and progesterone. Annu Rev Physiol 67: 335-376.

14. Richardson B, Price A, Wagner M, Williams V, Lorigan P, et al. (1999) Investigation of female survival benefit in metastatic melanoma. $\mathrm{Br} \mathrm{J}$ Cancer 12: $2025-2033$.

15. Gefeller O, Hassan K, Wille L (1998) Cutaneous malignant melanoma in women and the role of oral contraceptives. Br J Dermatol 138: 122-124.

16. Miller JG, Mac Neil S (1997) Gender and cutaneous melanoma. Br J Dermato 136: $657-665$

17. Shaw HM, McGovern VJ, Milton GW, Farago GA, McCarthy WH (1980) Malignant melanoma: influence of site of lesion and age of patient in the female superiority in survival. Cancer 46: 2731-2735.

18. Karjalainen S, Hakulinen T (1988) Survival and prognostic factors of patients with skin melanoma. A regression-model analysis based on nationwide cancer registry data. Cancer 62: 2274-2280.

19. Cocconi G, Bella M, Calabresi F, Tonato M, Canaletti R, et al. (1992) Treatment of metastatic malignant melanoma with dacarbazine plus tamoxifen. $\mathrm{N}$ Engl J Med 327: 516-523

20. Stidham KR, Johnson JL, Seigler HF (1994) Survival superiority of females with melanoma. A multivariate analysis of 6383 patients exploring the significance of gender in prognostic outcome. Arch Surg 129: 316-324.

21. MacKie RM, Bufalino R, Morabito A, Sutherland C, Cascinelli N (1991) Lack of effect of pregnancy on outcome of melanoma. For The World Health Organisation Melanoma Programme. Lancet 337: 653-655.

22. Slingluff CL Jr, Seigler HF (1992) Malignant melanoma and pregnancy. Ann Plast Surg 28: 95-99.

23. Shaw HM, Milton GW, Farago G, McCarthy WH (1978) Endocrine influences on survival from malignant melanoma. Cancer 42: 669-677.

24. Travers RL, Sober AJ, Berwick M, Mihm MC Jr, Barnhill RL, et al. (1995) Increased thickness of pregnancy-associated melanoma. Br J Dermatol 132 876-883.

25. Byrom L, Olsen C, Knight L, Khosrotehrani K, Green AC (2015) Increased mortality for pregnancy-associated melanoma: systematic review and metaanalysis. J Eur Acad Dermatol Venereol 29: 1457-1466.

26. Janik ME, Bełkot K, Przybyło M (2014) Is oestrogen an important player in melanoma progression? Contemp Oncol (Pozn) 18: 302-306

27. Cardonick E (2014) Pregnancy-associated breast cancer: optimal treatment options. Int J Womens Health 6: 935-943.

28. Enninga EA, Holtan SG, Creedon DJ, Dronca RS, Nevala WK, et al. (2014) Immunomodulatory effects of sex hormones: requirements for pregnancy and relevance in melanoma. Mayo Clin Proc 89: 520-535

29. Jhaveri MB, Driscoll MS, Grant-Kels JM (2011) Melanoma in pregnancy. Clin Obstet Gynecol 54: 537-545.

30. Mordoh J, Tapia IJ, Barrio MM (2013) A word of caution: do not wake sleeping dogs; micrometastases of melanoma suddenly grew after progesterone treatment. BMC Cancer 13: 132.

31. Fang X, Zhang X, Zhou M, Li J (2010) Effects of progesterone on the growth regulation in classical progesterone receptor-negative malignant melanoma cells. J Huazhong Univ Sci Technolog Med Sci 30: 231-234.
32. Ramaraj $P$, Cox JL (2014) In vitro effect of progesterone on human melanoma (BLM) cell growth. Int J Clin Exp Med 7: 3941-3953 eCollection 2014.

33. Kanda N, Watanabe S (2011) 17beta-estradiol, progesterone, and dihydrotestosterone suppress the growth of human melanoma by inhibiting interleukin-8 production. J Invest Dermatol 117: 274-283

34. Tucci P, Porta G, Agostini M, Dinsdale D, lavicoli I, et al. (2013) Metabolic effects of TiO2 nanoparticles, a common component of sunscreens and cosmetics, on human keratinocytes. Cell Death Dis Mar 21;4:e549.

35. Kajstura M, Halicka HD, Pryjma J, Darzynkiewicz Z (2007) Discontinuous fragmentation of nuclear DNA during apoptosis revealed by discrete "sub-G1" peaks on DNA content histograms. Cytometry A 71: 125-131.

36. Kubista M, Akerman B, Nordén B (1987) Characterization of interaction between DNA and 4',6-diamidino-2-phenylindole by optical spectroscopy. Biochemistry 26: 4545-4553

37. Serafino A, Balestrieri E, Pierimarchi P, Matteucci C, Moroni G, et al. (2009) The activation of human endogenous retrovirus $K$ (HERV-K) is implicated in melanoma cell malignant transformation. Exp Cell Res 315: 849-862.

38. Wang P, Henning SM, Heber D (2010) Limitations of MTT and MTS-based assays for measurement of antiproliferative activity of green tea polyphenols. PLoS One 5(4): e10202.

39. Büscher K, Trefzer U, Hofmann M, Sterry W, Kurth R, et al. (2005) Expression of human endogenous retrovirus $\mathrm{K}$ in melanomas and melanoma cell lines. Cancer Res 65: 4172-4180.

40. Li Z, Sheng T, Wan X, Liu T, Wu H, et al. (2010) Expression of HERV-K correlates with status of MEK-ERK and 16INK4A16ICDK4 pathways in melanoma cells. Cancer Invest 28: 1031-1037.

41. Ono M, Kawakami M, Ushikubo $H$ (1987) Stimulation of expression of the human endogenous retrovirus genome by female steroid hormones in human breast cancer cell line T47D. J Virol 61: 2059-2062.

42. Chlebowski RT, Anderson GL, Gass M, Lane DS, Aragaki AK, et al. (2010) Estrogen plus progestin and breast cancer incidence and mortality in postmenopausal women. JAMA 304: 1684-16892.

43. Tang JY, Spaunhurst KM, Chlebowski RT, Wactawski-Wende J, Keiser E, et al. (2011) Menopausal hormone therapy and risks of melanoma and nonmelanoma skin cancers: women's health initiative randomized trials. J Natl Cancer Inst 103: $1469-1475$

44. Govender Y, Avenant C, Verhoog NJ, Ray RM, Grantham NJ, et al. (2014) The injectable-only contraceptive medroxyprogesterone acetate, unlike norethisterone acetate and progesterone, regulates inflammatory genes in endocervical cells via the glucocorticoid receptor. PLoS One. May 19;9(5):e96497.

45. Hapgood JP, Ray RM, Govender Y, Avenant C, Tomasicchio M (2014) Differential glucocorticoid receptor-mediated effects on immunomodulatory gene expression by progestin contraceptives: implications for HIV-1 pathogenesis. Am J Reprod Immunol 71: 505-512.

46. Arroyo IC, Montor JM (2011) Non-reproductive effects of sex steroids: their immunoregulatory role. Curr Top Med Chem 11: 1661-1662.

47. Colditz GA, Rosner BA, Chen WY, Holmes MD, Hankinson SE (2004) Risk factors for breast cancer according to estrogen and progesterone receptor status. J Natl Cancer Inst 96: 218-228.

48. Whitley KA, Ural SH (2014) Treatment modalities in recurrent miscarriages without diagnosis. Semin Reprod Med 32: 319-322. 